\title{
ph

\section{La gestión del patrimonio cultural en el espacio natural de Doñana}

Patxi Serveto i Aguiló | espacio natural de Doñana, Consejería de Medio Ambiente y Ordenación del Territorio, Junta de Andalucía

URL de la contribución <www.iaph.es/revistaph/index.php/revistaph/article/view/3480>

\section{RESUMEN}

En la gestión de los espacios naturales protegidos se produce una constante evolución conceptual en la consideración del patrimonio cultural, tanto en relación a su existencia como a su papel, habiendo progresado desde la práctica ausencia hasta el futuro horizonte de la consideración del patrimonio integral, natural y cultural. La justificación estriba no solo en la admisión de su valor intrínseco, sino en su propia relación sinérgica respecto de la conservación de la naturaleza.

Conscientes de ello, en estos últimos años se están desarrollando una serie de actuaciones relativas al patrimonio cultural de Doñana dirigidas, de un lado, a ampliar las disciplinas del mismo que se tienen en cuenta y, de otro, a madurar la plena inclusión de dicho patrimonio en la gestión del espacio natural. Uno de los hitos que están contribuyendo a ello es la futura incoación del expediente de inclusión del parque nacional de Doñana como zona patrimonial, nueva figura de protección del patrimonio histórico desde una perspectiva territorial.

En este sentido, y puesto que en la actualidad se están revisando los instrumentos de planificación del espacio natural de Doñana, se pretende avanzar en la integración del patrimonio cultural, así como del paisaje, en la gestión del mismo mediante la implementación de diversas medidas, mecanismos y herramientas, aspecto este que contribuirá a que Doñana siga constituyendo un referente como espacio natural protegido.

\footnotetext{
Palabras clave

Espacios naturales | Paisaje | Paisaje cultural | Parque Nacional de Doñana | Patrimonio cultural | Patrimonio natural | Planificación | Plan sectorial | Zona patrimonial |
} 


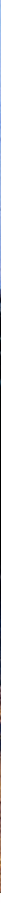


"Aparte del esplendor de su fauna y su flora, Doñana esgrime la clave de su propia cultura milenaria, esa especie de réplica del jardín de las Hespérides tutelado por una ley magnífica: la que sostiene el equilibrio de la biosfera, pero también la estabilidad de ese fondo primigenio donde se fusionan la leyenda y la historia"

Los poderes de Doñana. J. M. Caballero Bonald

\section{INTRODUCCIÓN}

\section{El patrimonio cultural en los espacios naturales protegidos}

Para tratar sobre la gestión del patrimonio cultural de Doñana, como espacio natural protegido, es necesario realizar un somero repaso sobre la evolución que ha experimentado el concepto de patrimonio en estos espacios, en un proceso quizás aún inconcluso en nuestro país. En este sentido, pueden distinguirse tres planteamientos relativos a la consideración que el patrimonio puede tener en un espacio natural protegido: el patrimonio natural predominante; el patrimonio cultural complemento del patrimonio natural; y el patrimonio integral como interacción de los patrimonios natural y cultural.

\section{El patrimonio natural predominante}

La declaración de los primeros espacios naturales protegidos se produjo por la necesidad de conservar intactos determinados territorios que destacaban por su exuberante naturaleza, consecuencia de la idea romántica de exaltación de los parajes "salvajes".

Fue en Estados Unidos cuando se estableció el primer paradigma de conservación de la naturaleza, declarándose el parque nacional de Yellowstone (1872); nacía el concepto de parque nacional, definido como "Un lugar para poner al abrigo de toda depredación humana las bellezas naturales más destacadas de un país; para favorecer, mediante la vida en la naturaleza, la educación, el esparcimiento y el entretenimiento del pueblo". La idea se extendió a Europa a comienzos del siglo XX, también a España pero de un modo innovador, ya que comenzó aprobando la que se considera primera ley de parques nacionales en el mundo (1916), que los definía como "aquellos sitios o parajes excepcionalmente pintorescos, forestales o agrestes del territorio nacional, que el Estado consagre, declarándolos como tales, con el exclusivo objeto de favorecer su acceso por vías de comunicación adecuadas, y de respetar y hacer que se respete la belleza natural de sus paisajes, la riqueza de su fauna y de su flora y las particularidades geológicas e hidrológicas que encierren, evitando de este modo con la mayor eficacia todo acto de destrucción, deterioro o desfiguración por la mano del hombre". 
La Unión Internacional para la Conservación de la Naturaleza (UICN), primera organización medioambiental del mundo (1948), también definió posteriormente el término parque nacional: "Son áreas relativamente amplias, donde uno o varios ecosistemas no se han visto materialmente alterados por la explotación y ocupación humana, donde las especies vegetales y animales, las formaciones geomorfológicas y los hábitats, son de especial interés científico, educativo y recreativo, o contienen un paisaje natural de gran belleza; donde la máxima autoridad competente del país ha tomado las medidas para prevenir o eliminar lo antes posible la explotación u ocupación de todo el área, y para hacer cumplir de modo efectivo el respeto por los rasgos ecológicos, geomorfológicos y estéticos que motivaron su establecimiento; donde se permite entrar a los visitantes bajo condiciones especiales, con propósitos de inspiración, educativos, culturales y recreativos".

En 1971 la UNESCO inició el Programa hombre y biosfera (Man and Biosphere -MaB-), con el objetivo de establecer un nuevo modelo de relación entre el ser humano y la naturaleza, promoviendo la armonización de la conservación de la naturaleza con el beneficio de los recursos naturales. Entre sus líneas de actuación creó la figura de reserva de la biosfera, definida como "Conjunto de áreas protegidas enlazadas gracias a un sistema internacional coordinado, que permitiera mostrar tanto la importancia de la conservación como la relación de esta con el desarrollo". Aunque el término "conservación" se refería a la naturaleza, uno de los criterios que justificaban la declaración de una reserva era que constituyera un "Ejemplo de paisaje armonioso resultante de modalidades tradicionales de uso de la tierra". A pesar de ello, las primeras reservas solían coincidir con figuras de conservación emblemáticas, como la declaración como reserva de la biosfera del parque nacional de Doñana (1980).

\section{El patrimonio cultural complemento del patrimonio natural}

Paulatinamente, se tuvo cada vez en mayor consideración la existencia del patrimonio cultural en los espacios naturales protegidos, tanto como valor en sí mismo como recurso que sumar al valor natural. En este sentido existe una evidente identificación entre el patrimonio cultural, material e inmaterial, y los usos y aprovechamientos de los recursos naturales llevados a cabo por la tradición popular, que cuanto menos han permitido la conservación de los sistemas naturales.

Así pues, fruto de los avances que se estaban produciendo en conservación de la naturaleza, a comienzos de los años 70 del pasado siglo nuestro país aportó la figura de parque natural (Ley 15/1975, de espacios naturales protegidos), uno de cuyos objetivos era armonizar la conservación de los valores naturales con el aprovechamiento ordenado de los recursos, en sintonía con las reservas de la biosfera. 

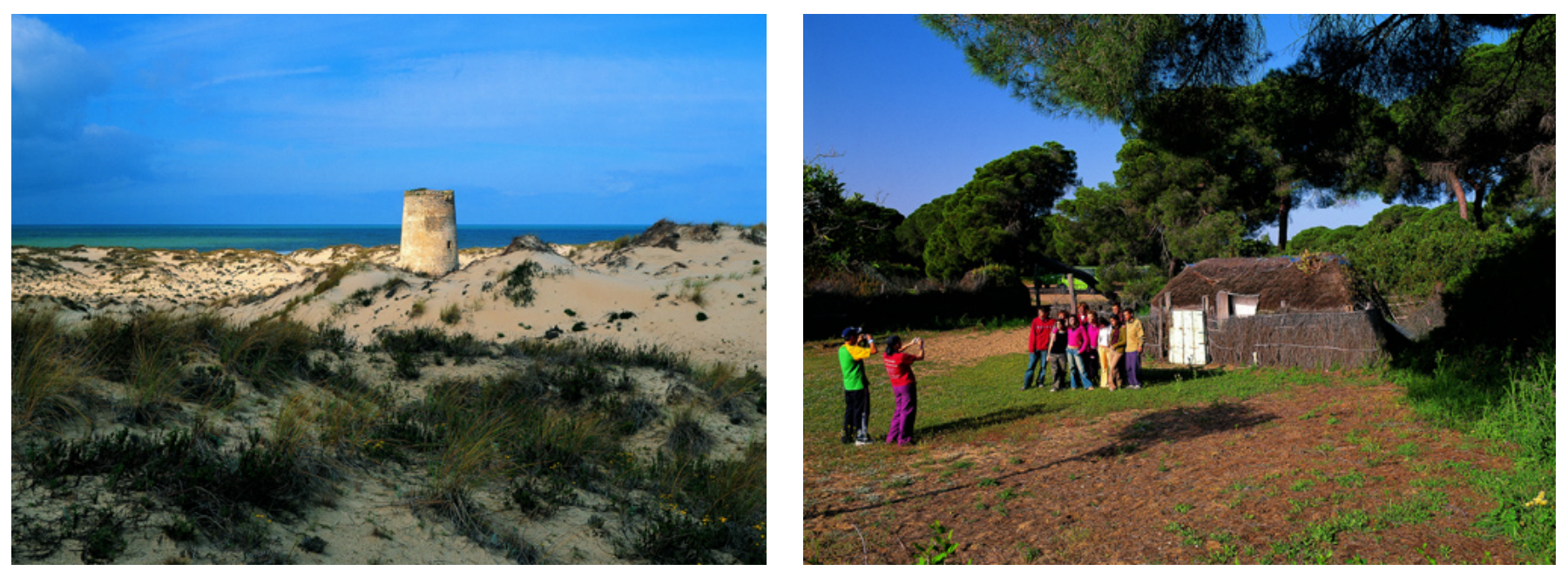

Torre almenara de Carbonero, en el parque nacional

Escolares del programa de educación ambiental Doñana Entorno visitando el poblado de chozas de La Plancha | fotos Patxi Serveto (PAREJO DELGADO; SERVETO AGUILÓ, 2008)
El I Congreso mundial del programa MaB (Bielorrusia, 1983) Ilamó la atención sobre el modelo de desarrollo compatible que debían atender las reservas, el cual se institucionalizó en la segunda Cumbre de la Tierra (Río de Janeiro, 1992) como "desarrollo sostenible", de tanta repercusión en los conceptos "conservación de los recursos naturales" y "desarrollo socioeconómico". La aplicación práctica de la figura de reserva de la biosfera se impulsó tras el II Congreso mundial (Sevilla, 1995), al consagrar que la promoción del desarrollo de las poblaciones locales constituye una de sus funciones básicas, junto a la conservación de la biodiversidad y de los recursos naturales y culturales. Pero la aportación de mayor interés en relación al patrimonio cultural se realizó en el Plan de acción del Montseny 2009-2013, adaptación española del Plan de acción de la red mundial (III Congreso mundial. Madrid, 2008); en él se propuso la "Realización de inventarios o catálogos de elementos culturales y etnográficos", así como la "Elaboración de planes de protección y recuperación, reconocimiento y valorización de las culturas locales y del patrimonio etnográfico". En ese mismo año la UICN estableció la definición genérica de área protegida: "Un espacio geográfico claramente definido, reconocido, dedicado y gestionado, mediante medios legales u otros medios eficaces, para conseguir la conservación a largo plazo de la naturaleza y sus servicios ecosistémicos y sus valores culturales asociados".

Con anterioridad, la ley de creación del Espacio Natural de Doñana (LEY 8/1999) no aportaba avance alguno en relación a la consideración del patrimonio cultural, limitándose a indicar que "[...] [su] utilización [...] se llevará a cabo con las cautelas que reglamentariamente se establezcan" (art. 28), mientras que de los "recursos paisajísticos" se manifiesta preferencia expresa al "paisaje natural" (art. 27). 

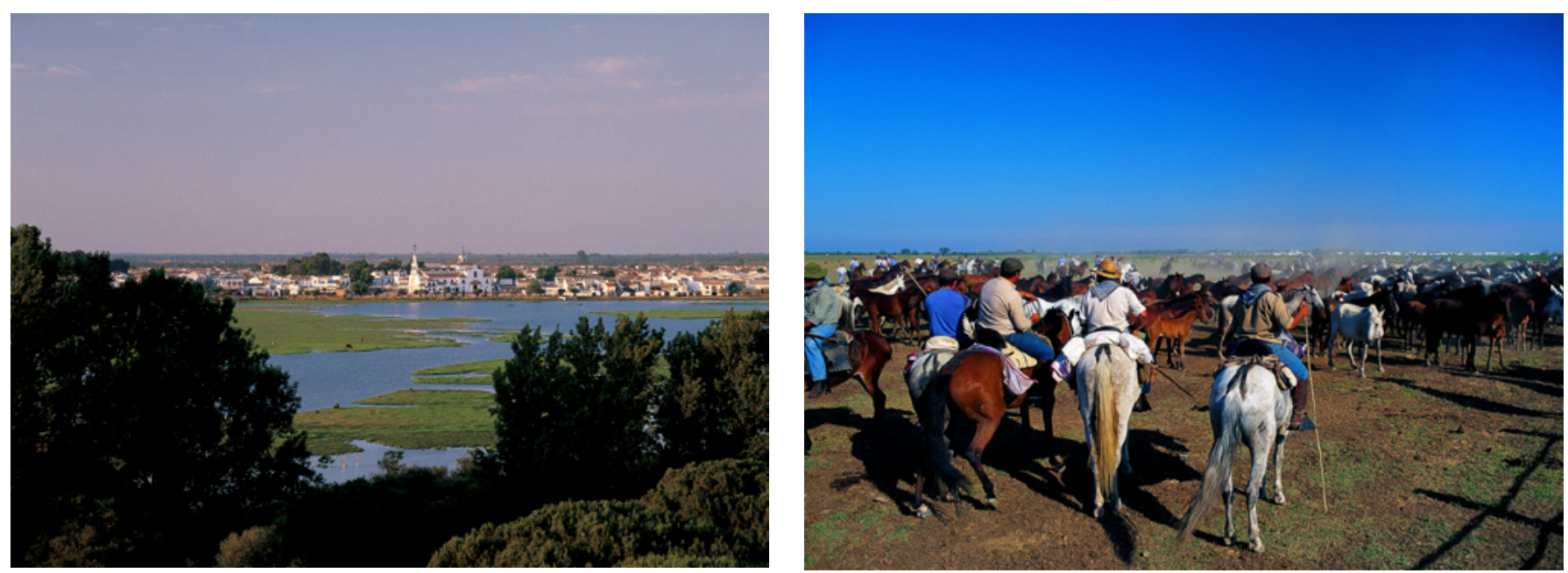

Asimismo, no fue hasta 2002 cuando la Convención sobre los humedales de importancia internacional (Ramsar, 1971) trató los aspectos culturales de estos espacios, dedicándole la celebración del Día Mundial de los Humedales y editando la primera publicación al respecto (VIÑALS, 2002).

La legislación básica española relativa al patrimonio natural y la biodiversidad (LEY 42/2007) contiene avances relativos fundamentalmente al paisaje, al adaptar su definición al Convenio europeo del paisaje (Florencia, 2000). Destaca como objetivo principal de la figura de paisaje protegido "La preservación de la interacción armoniosa entre la naturaleza y la cultura [...] -procurándose- [...] el mantenimiento de las prácticas de carácter tradicional que contribuyan a la preservación de sus valores y recursos naturales"; al respecto, promueve la realización del "inventario español de los conocimientos tradicionales relativos al patrimonio natural y la biodiversidad".

En el Programa de trabajo para las áreas protegidas 2009-2013 (EUROPARCEspaña $)^{1}$ el patrimonio cultural solo figura explícitamente en una de sus líneas de trabajo, incluyéndose en la práctica únicamente los valores inmateriales. La propia justificación de esta línea confirma nuestra valoración general: "El reconocimiento de los valores inmateriales, espirituales y culturales vinculados a los espacios naturales protegidos, y la necesidad de su incorporación en la planificación, gestión y promoción de los mismos, se ha ido consolidando gradualmente desde el Congreso mundial de parques de 2003, hasta incorporarse en diversos programas de actuación y estrategias de la UICN, del Convenio de diversidad biológica, y de la propia Federación EUROPARC. En España aún es muy incipiente el reconocimiento explícito de estos valores".
La aldea de El Rocío desde el parque nacional

Saca de las yeguas, en el parque nacional | fotos Patxi Serveto (PAREJO DELGADO; SERVETO AGUILÓ, 2008)
1

EUROPARC-España es una organización en la que participan las instituciones implicadas en la gestión de los espacios protegidos en España; creada en 1993, pertenece a la Federación EUROPARC, organización paneuropea fundada en 1973 que reúne instituciones de 39 países dedicadas a la gestión de áreas protegidas y defensa de la naturaleza. 


\section{Manual 10}

Serie de manuales EUROPARC-España Programa de trabajo para las áreas protegidas 2009-2013

El patrimonio inmaterial: valores culturales y espirituales Manual para su incorporación en las áreas protegidas

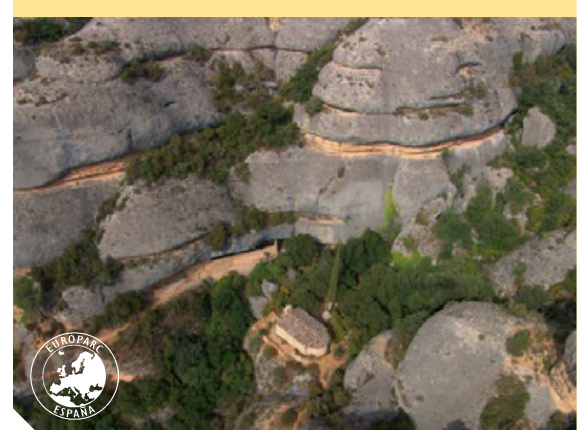

Cubierta de El patrimonio inmaterial: valores culturales y espirituales

\section{El patrimonio integral como interacción de los patrimonios natural y cultural}

El concepto de patrimonio integral surge a partir de la aplicación de un enfoque holístico a la interacción entre los patrimonios natural y cultural de un territorio, permitiendo hacer un análisis, desde una perspectiva sistémica, de su realidad natural, social e histórica, que es la que conforma la memoria colectiva local. Una de las figuras internacionales que más ha contribuido a la consideración integral del patrimonio ha sido la Convención para la protección del patrimonio mundial cultural y natural (UNESCO, 1972), establecida con la premisa de que algunos lugares tienen un valor universal excepcional, formando parte del patrimonio de la humanidad. Su originalidad residió en que vinculaba en una misma finalidad el concepto de preservación de los sitios culturales y la conservación de la naturaleza, destacando su complementariedad. Los lugares candidatos deben cumplir alguno de los criterios para bienes culturales o para bienes naturales, inscribiéndose como sitios mixtos si cumplen simultáneamente algún criterio de ambos. Pese a ello, de las estadísticas se deduce que aún existen reticencias para considerar como mixtos espacios de los que se resalta solo su patrimonio natural, como podría ser el caso de Doñana, cuya inclusión del parque nacional en la Lista de patrimonio natural mundial (1994) podría haberse justificado como sitio mixto.

En nuestro país también está incorporándose esta concepción integral del patrimonio de los espacios naturales protegidos, como ya ocurre en ciertos países anglosajones. El vigente Plan director de la Red de parques nacionales (REAL DECRETO 1803/1999), afirma que "los parques nacionales constituyen una red orientada a configurar un modelo de gestión conservacionista en donde se presta atención singular a la riqueza en diversidad biológica y a la evolución conjunta de los sistemas naturales y de los sistemas culturales", para continuar "En nuestros días el conservar los parques nacionales incorpora tanto la gestión activa del medio natural como el respeto a los rasgos identificativos de tradición y cultura que han contribuido a modelar paisajes".

\section{Los diversos ámbitos de Doñana}

Antes de tratar el patrimonio cultural de Doñana resulta conveniente clarificar su estatus normativo, ya que sus diversas figuras de protección implican diferentes instrumentos de planificación y gestión.

El inicio de la protección del patrimonio natural de Doñana se produjo con la fundación de la reserva biológica en 1964, a partir de la cual se decretó el Parque Nacional de Doñana en 1969, posteriormente ampliado con la denominada Ley de Doñana (Ley 91/1978).

Los valores patrimoniales de Doñana permitieron que se sucedieran los reconocimientos internacionales, declarándose reserva de la biosfera en 1980, e 
incluyéndose en 1982 en la Lista de zonas húmedas de importancia internacional, a la que se sumó el parque natural en 2005. En 1985, el Consejo de Europa otorgó al parque nacional el Diploma europeo, y en 1988 fue declarado zona de especial protección para las aves (Directiva 79/409/CEE de la UE), ampliada posteriormente al conjunto del espacio natural (2002), declarado de igual modo como zona especial de conservación de la Red ecológica europea natura 2000 (Directiva 92/43/CEE de la UE). Asimismo, el parque nacional de Doñana se inscribió en la Lista de patrimonio mundial en 1994, a los 25 años de su creación.

Previamente, la Junta de Andalucía había declarado el Parque Natural Entorno de Doñana (LEY 2/1989), ampliando más tarde sus límites y denominándolo Parque Natural de Doñana. Con posterioridad, la Junta estableció la gestión única del parque nacional y parque natural, mediante la creación de la figura del espacio natural de Doñana (LEY 8/1999), ratificada en lo
El ámbito geográfico del espacio natural de Doñana y sus diversas figuras de protección | mapa Justo Jiménez (Espacio Natural Doñana, 2014)

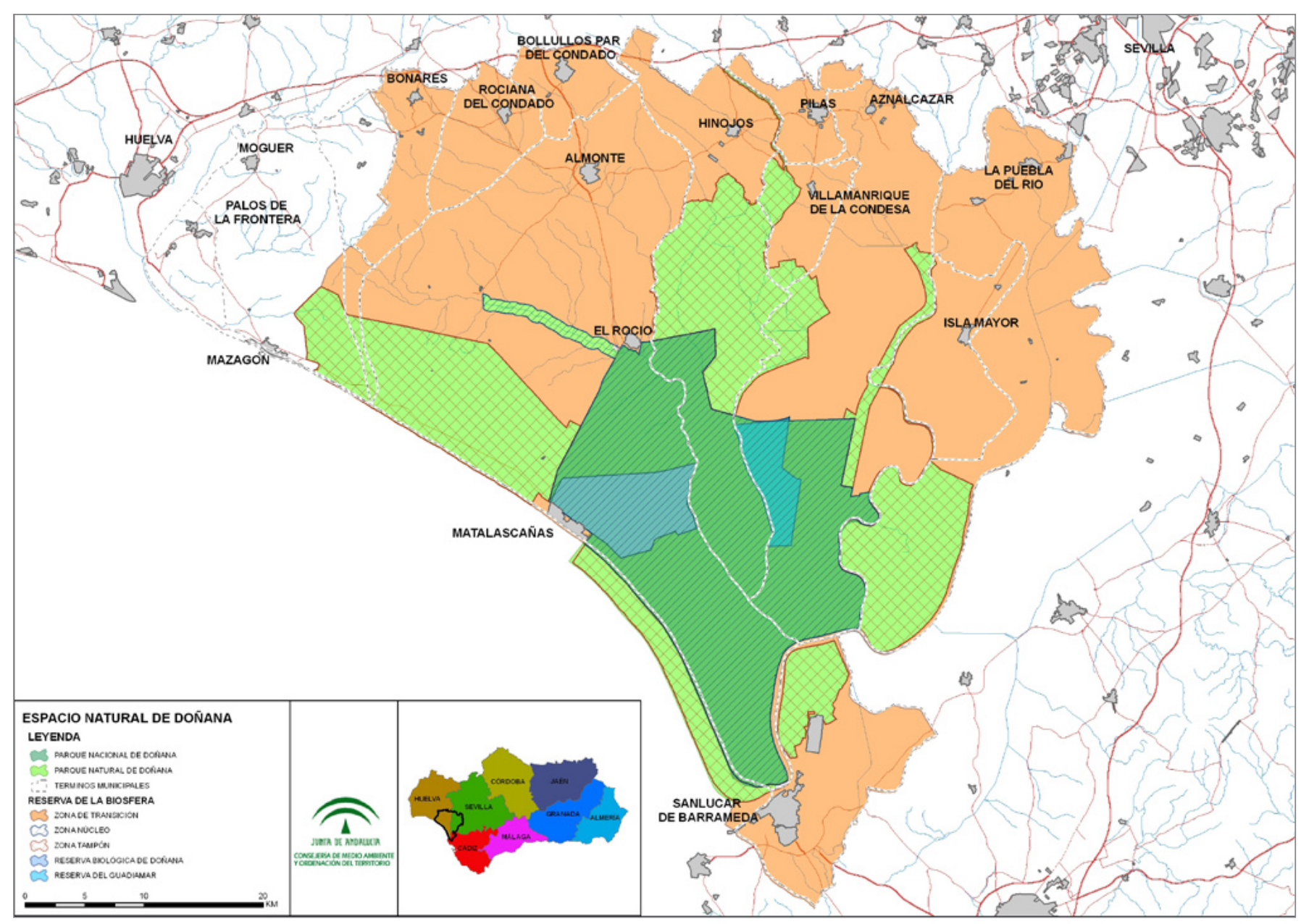


sustancial por la sentencia del Tribunal Constitucional (194/2004), que otorgaba a las comunidades autónomas la gestión de los espacios naturales protegidos; de esta forma, se pudo establecer la ordenación integrada de ambos parques (Decreto 97/2005).

A comienzos del nuevo milenio se declararon los monumentos naturales acantilado del Asperillo,acebuches de El Rocío y el pino centenario del Parador de Mazagón. Y, por último, desde 2012 la reserva de la biosfera de Doñana ha sido ampliada hasta los catorce municipios que integran el área de influencia socioeconómica del espacio natural, constituyendo actualmente el referente más extenso de protección territorial de Doñana.

\section{EL PATRIMONIO CULTURAL DE DOÑANA}

En primer lugar, se exponen tres iniciativas cuya vocación ha sido tratar el conjunto del patrimonio cultural de Doñana, aunque sobre diferentes ámbitos territoriales.

\section{Recuperación del patrimonio cultural. Doñana y su entorno}

Entre los años 1988 y 1992 un equipo multidisciplinar (Instituto de la Juventud) llevó a cabo un estudio de investigación en el parque nacional de Doñana y en el que por entonces se denominaba a su zona de influencia "entorno"; constituyó todo un hito, al aplicar una metodología multidisciplinar innovadora e integral, constituyendo con el paso de los años una base bibliográfica fundamental de referencia del patrimonio cultural de Doñana.

Se llevó a cabo a través de campañas anuales, cuyo resultado se plasmó en trece volúmenes, cuyas contadas copias se entregaron, además de los originales para el Instituto, a algunas entidades vinculadas a la gestión y conservación de Doñana. Es por tanto intención del espacio natural recuperar y poner a disposición fundamentalmente del ámbito técnico e investigador esta documentación inédita (FUREST GUTIERREZ; ESTÉVEZ HERRANZ, 19881992), de un excepcional valor histórico, mediante la edición de una reproducción facsímil digital; de igual modo se prevé proceder con otras obras capitales descatalogadas, como Organización del Territorio en Doñana y su Entorno próximo (Almonte). Siglos XVIII-XX (OJEDA RIVERA, 1987) y Pan de marisma (ACOSTA NARANJO, 2004).

La denominación de cada uno de los volúmenes del estudio, tal como se elaboraron cronológicamente, es la siguiente: I. Acercamiento a Doñana y su Entorno; II. Identificación de Unidades Ambientales; III. Unidad Litoral 1; IV. Unidad Litoral 2; V. Unidad Agrosistemas Tradicionales 1. Subunidad Aljarafe; VI. Subunidad Aljarafe; VII. Unidad Marismas y otros Espacios 
Naturales 1; VIII. Unidad Marismas y otros Espacios Naturales 2; IX. Unidad Marismas y otros Espacios Naturales 3; X. Unidad Marismas y otros Espacios Naturales 4; XI. Marismas Transformadas; XII. Agrosistemas Tradicionales; XIII. El Abalario.

\section{El patrimonio cultural de la comarca de Doñana}

La recopilación del patrimonio cultural de la comarca de Doñana ha sido realizada por la Fundación Doñana $21^{2}$, fundamentalmente con fines divulgativos orientados a su valorización turística:

"Así, cuando se hace referencia a la Comarca de Doñana se realiza desde un enfoque integrado en el que se incluyen los términos de 14 municipios distribuidos por las tierras del Condado de Huelva, Lugares Colombinos, Aljarafe Sevillano, Marismas y Bajo Guadalquivir, extendiéndose por casi $300 \mathrm{~km}^{2}$ dentro de ese triángulo que formarían Huelva, Sevilla y Cádiz y con una población que supera los 180.000 habitantes.

$[\ldots]$

Si se pudiera señalar una manifestación que sirviera de nexo de unión entre todos los municipios de la Comarca y que incluso transciende a todo el territorio andaluz, se trataría sin duda del fervor popular en torno a la Virgen de El Rocío,[...] que ha llegado a convertirse en el principal centro de devoción popular de Andalucía. Los caminos que llevan a los peregrinos hasta la Ermita parten desde todos los puntos cardinales de la comarca de Doñana, favoreciendo a la preservación de antiguas vías pecuarias; uno más de los interesantes recursos culturales y turísticos de este territorio.

Otro de los elementos identitarios del Patrimonio de Doñana, es el que representa el caballo, símbolo de esta Comarca y que forma parte indisoluble de su acervo cultural. Vinculado a la marisma y al monte, era un elemento esencial en las faenas agrícolas, y en la actualidad sigue ligado a las fiestas y al ocio. [...] Otros acontecimientos como la 'Saca de las Yeguas' en Almonte o las 'Carreras de Caballos en la Playa' en Sanlúcar de Barrameda, vienen a testimoniar la ancestral relación de la población local de Doñana con el mundo del caballo.

La gastronomía también es un reflejo de los recursos que ofrece el medio; desde productos marismeños a la suculenta aportación del mar y la tierra,[...] sin olvidar la producción de los exquisitos vinos del Condado de Huelva y la apreciada Manzanilla de Sanlúcar de Barrameda.

El ciclo festivo de estos municipios es muy amplio [...]. Así, las Cruces de Mayo de Bonares, el Corpus Christi de Hinojos o La Puebla del Río, las Carreritas de Pilas, la Romería de Montemayor de Moguer y las diversas manifestaciones de la Semana Santa son sólo algunos ejemplos de la rica religiosidad popular de estas tierras" (MATEOS MATEOS, 2011: 08-14).
2

La Fundación para el Desarrollo Sostenible de Doñana y su Entorno -Doñana 21-, de carácter público, nace en 1997 merced al primer Plan de Desarrollo Sostenible de Doñana, con el objeto de actuar como agencia de dinamización y desarrollo socioeconómico, sostenible, de la comarca.

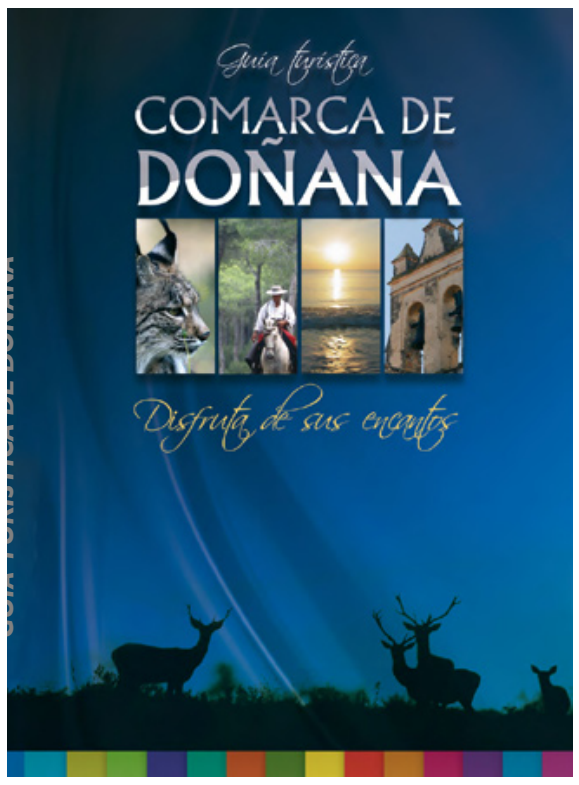

Cubierta de la Guía turística comarca de Doñana. Disfruta de sus encantos 


\section{Zona patrimonial de Doñana}

En 2013, la Consejería de Cultura y Deporte comenzó la tramitación del expediente relativo a la Documentación técnica para la inscripción en el Catálogo general del patrimonio histórico de Andalucía del conjunto de bienes inmuebles y actividades etnológicas en el parque nacional de Doñana como bien de interés cultural con la tipología de zona patrimonial.

Esta iniciativa de la delegación territorial de Huelva, en la que ha colaborado el espacio natural Doñana, tiene su marco normativo en la Ley del patrimonio histórico de Andalucía (LEY 14/2007), donde la zona patrimonial aparece como nueva figura de protección desde una perspectiva territorial; además, se encuadra en el Acuerdo marco de colaboración suscrito entre las consejerías de Cultura y de Medio Ambiente (2011), que establece la voluntad de tutela del patrimonio cultural en el contexto de los espacios naturales protegidos de Andalucía.

El ámbito de la zona patrimonial propuesta no incluye aquellos inmuebles y actividades del parque ubicados en la provincia de Sevilla, por lo que se estima imprescindible su ampliación futura al resto del parque nacional, valorándose en el futuro su ampliación también al parque natural de Doñana.

En anexo adjunto (ver pp. 47-50) se incluyen algunos textos ilustrativos pertenecientes a la ficha general de la Documentación técnica (SEÑO ASENCIO, 2012: 04-12, 35-36).

LAS EDIFICACIONES EN DOÑANA: ESTRATEGIAS DE EFICIENCIA

José Maria Rincón Calderón
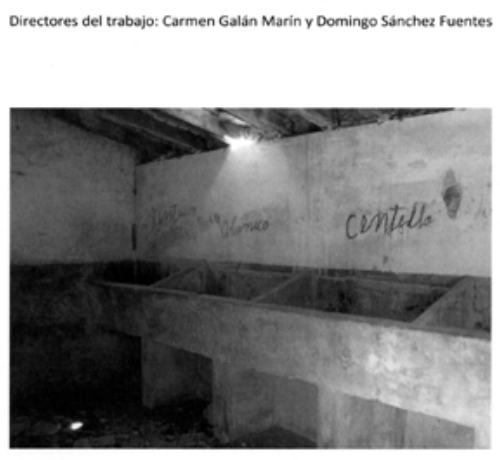

Trabajo Fin de Mastser - Edición 2011-2012 Universidad de Sevilla

Cubierta de Las edificaciones en Doñana: estrategias de eficiencia

\section{ACTUACIONES SOBRE EL PATRIMONIO CULTURAL DE DOÑANA}

Se exponen a continuación diversas actuaciones específicas realizadas, bien desde el propio END bien promovidas por éste, algunas de ellas a partir de las determinaciones establecidas en el vigente Plan rector de uso y gestión del parque nacional; con ellas se ha ampliado el espectro del patrimonio cultural considerado en el espacio natural, contribuyendo a madurar el concepto de gestión del patrimonio cultural completo (material, inmaterial y artístico) con el horizonte del patrimonio integral.

\section{Patrimonio cultural material}

\section{Las edificaciones en Doñana: estrategias de eficiencia}

Responsable: José María Rincón Calderón.

Trabajo fin de máster Ciudad y arquitectura sostenibles de la Universidad de Sevilla, edición 2011-2012.

Prospección de investigación n. 0 09/2012 del espacio natural Doñana/estación biológica de Doñana-CSIC. 
El objetivo genérico de esta actuación ha consistido en plantear alternativas y soluciones para la conservación del patrimonio construido habitacional en un medio natural tan singular como Doñana. Como reseña de este trabajo se incluye un extracto del resumen de su comunicación:

"El hombre siempre ha habitado Doñana, manteniendo una relación compleja con ese entorno complejo; en algunos aspectos de su comportamiento, casi se ha confundido con la naturaleza de Doñana: sus modos de vida, hábitos, espacios, se han mimetizado con los naturales y ha utilizado ese confundirse como estrategia de supervivencia. $Y$ la presencia del hombre conlleva la aparición de la edificación, para cubrir las necesidades básicas de cobijo, refugio y apoyo a las actividades productivas del ser humano. En contra de la idea generalizada, es notable la cantidad de edificaciones que han existido y siguen existiendo hoy en Doñana. La incorporación a las valoraciones patrimoniales asociadas a Doñana de otro tipo de cuestiones ajenas a las puramente naturales (culturales, sociales, etnológicas, etc.) reconoce a las edificaciones como exponente de estos valores. Las construcciones que se ubican en el parque, con su diversidad de fechas de construcción y estado de conservación, son testigos y huellas físicas de la relación entre el habitante de Doñana y ese particular medio físico. Han desaparecido edificaciones en Doñana; otras, se hallan actualmente en un proceso de degradación física y funcional que nos lleva a plantearnos cómo resolver la cuestión de la conservación de lo construido en un medio natural tan singular. Estas inquietudes nos dan la oportunidad de valorar la situación actual y especular sobre su futuro inmediato" (RINCÓN CALDERÓN; SÁNCHEZ FUENTES; GALÁN MARÍN, 2014: 40).

\section{Patrimonio cultural inmaterial}

Identificación, inventario y análisis de las variedades agrícolas tradicionales presentes en la reserva de la biosfera de Doñana

Responsable: Universidad de Sevilla, Departamento de Antropología Social, Grupo de Investigación Cultura, Ecología y Desarrollo de Pequeños Territorios (GICED), y Gestión Integral Agrícola del Sur-Consultores, S.L.

Proyecto de investigación promovido por el Espacio Natural Doñana y coordinado por la Fundación Doñana 21 en el marco de un Convenio de colaboración suscrito entre el Ministerio de Medio Ambiente y Medio Rural y Marino, y la Consejería de Medio Ambiente, para la ejecución del Programa de apoyo a la coordinación y gestión de actuaciones de desarrollo sostenible en las reservas de la biosfera de Andalucía (RESOLUCIÓN de 26 de enero de 2010), llevado a cabo entre 2011 y 2012.

El objetivo genérico de esta actuación ha consistido en desarrollar un proyecto demostrativo de recopilación de los métodos agrarios tradicionales de reproducción y abastecimiento de semillas, basados en el conocimiento local de conservación de las variedades autóctonas. Como reseña de este trabajo 


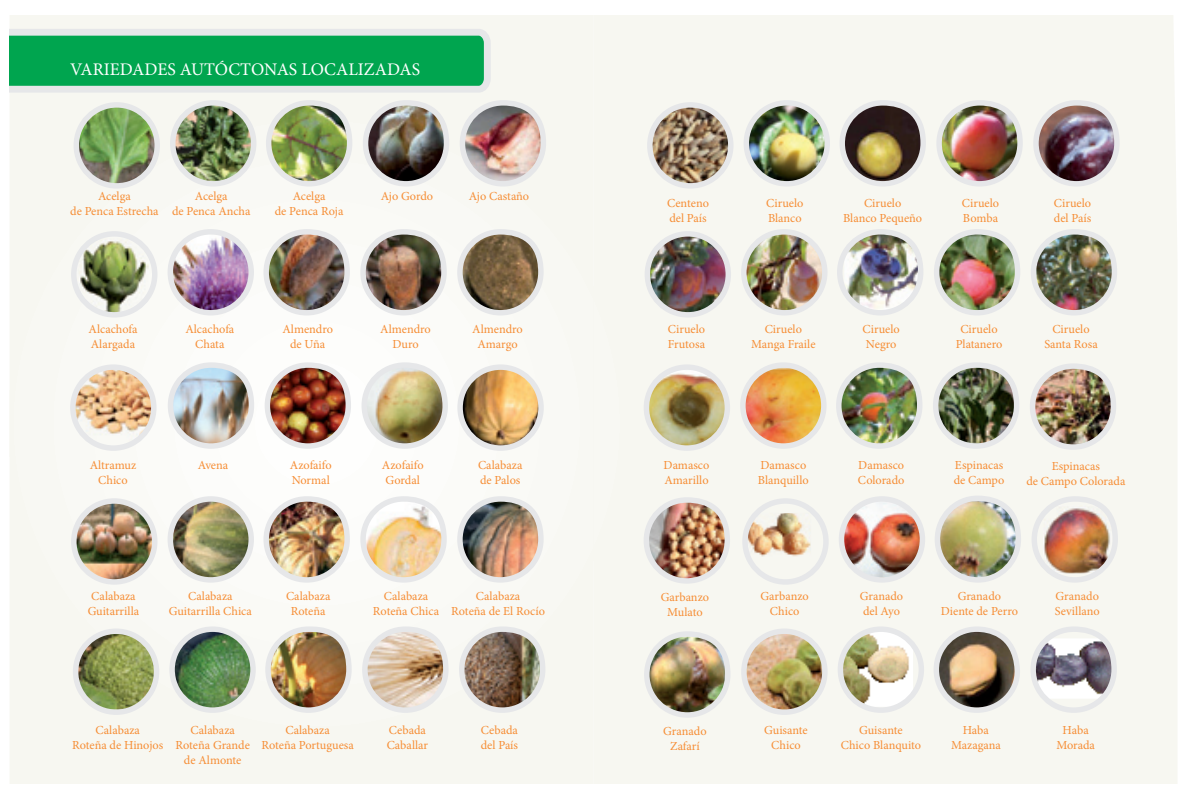

Dos carillas interiores del folleto divulgativo El fortalecimiento de la biodiversidad en Doñana

se incluye un extracto de la introducción de su informe final:

"[...] se presentan los resultados de las acciones llevadas a cabo durante los años 2011 y 2012 en cinco municipios del entorno de Doñana como respuesta al objetivo de apoyar la biodiversidad cultivada y el conocimiento local en áreas Reserva de la Biosfera, como es el Espacio Natural Protegido de Doñana. El área circundante a Doñana delimitada a efectos de este proyecto y según diferentes variables como mayor presencia de agroecosistemas y existencia de investigaciones previas en esta temática -agrobiodiversidad y conocimiento local asociado-, está conformada por cinco de los 14 municipios que integran la Comarca de Doñana. Estos cinco son: Rociana del Condado, Bollullos Par del Condado, Almonte, Hinojos y Villamanrique.

En estos municipios existe un gran potencial de recuperación, conservación y propagación de la biodiversidad cultivada todavía existente, la cual se mantiene, no sin dificultades, gracias al esfuerzo de un reducido número de agricultores, la mayor parte de ellos jubilados, que dedican gran parte de su ocio al cultivo de variedades locales en los ruedos próximos a los núcleos urbanos, con el fin de producir alimentos para el consumo familiar, aunque algunos también comercialicen sus productos. La gran mayoría de mantenedores cultiva estas variedades de huerto, frutales y forrajeras gracias a un corpus de conocimientos tradicionales que han aprendido a lo largo de su vida durante los procesos de trabajo y transmitidos como herencia de los más mayores, como parte de su cultura, respondiendo a las lógicas de la multifuncionalidad y el aprovechamiento óptimo de los recursos que han acompañado en su historia a los trabajadores del campo. 
La recuperación de estos saberes asociados al cultivo de especies tradicionales es una urgente tarea que debe ser acometida si no se quiere perder también este patrimonio inmaterial de los pueblos del Entorno de Doñana, que además tienen el potencial de convertirse en el germen de las cada vez más demandadas estrategias de gestión sostenible del medio" (FORTALECIMIENTO, 2012: 05-06).

\section{Etnozoología de Doñana}

Responsables: Manuel Pedro Cobo López y Raúl Elías Tijera Jiménez, Mancomunidad de Desarrollo y Fomento del Aljarafe.

Subvención acogida al Proyecto para la realización de actividades en las áreas de influencia socioeconómica del parque nacional de Doñana, convocatoria 2008, de la Consejería Medio Ambiente.

Prospección de investigación n. ${ }^{\circ}$ 23/2012 del espacio natural Doñana/estación biológica de Doñana-CSIC, llevada a cabo entre 2010 y 2013.

El objetivo genérico de esta actuación, que cierra una trilogía, ha consistido en estudiar la relación histórica del ser humano con su entorno de Doñana, haciendo hincapié en el uso y aprovechamiento de los recursos naturales que han fomentado la conservación del patrimonio natural. Como reseña de este trabajo se incluye un extracto del resultado de su informe final:

"[...] Pero Doñana no se podría explicar sin la huella que ha dejado la continuada presencia de las gentes de su entorno y los usos que tradicionalmente se ha realizado en sus tierras. Tan importante como la gea y los otros seres vivos, son los hombres y mujeres que han vivido en y del espacio natural del Parque Nacional, Parque Natural y su entorno. Estos habitantes han aprovechado los recursos naturales y ha generado toda una cultura medioambiental que, con las condiciones de vida actuales, va en vía de extinción.

Dentro de estos recursos, los animales han sido fundamentales en la vida cotidiana. Aunque hoy en día sigue existiendo relación con la fauna, el abandono progresivo, generalizado y lógico de estos aprovechamientos se debe a su falta de rentabilidad, a la necesidad de protección legal de la naturaleza que controle y vigile su explotación, a los cambios de hábitos y a la dureza que conlleva las labores del campo según los parámetros actuales de sacrificio y dedicación, por lo que estamos asistiendo a la desaparición de muchos de estos usos de los cuales, en breve, sólo quedará referencia en los museos, los documentales y los libros.

$[\ldots]$

A más de 600 especies animales diferentes han dado uso los habitantes de Doñana de las formas más diversas, principalmente con fines culinarios pero también medicinales, lúdicos, mágicos, para ayudar en las faenas o porque ocasionan algún peligro. Encontramos más de 160 invertebrados, 195 peces, 6 anfibios, 13 reptiles, 26 mamíferos y 206 aves" (COBO LÓPEZ; TIJERA JIMÉNEZ, 2013: 1-2).

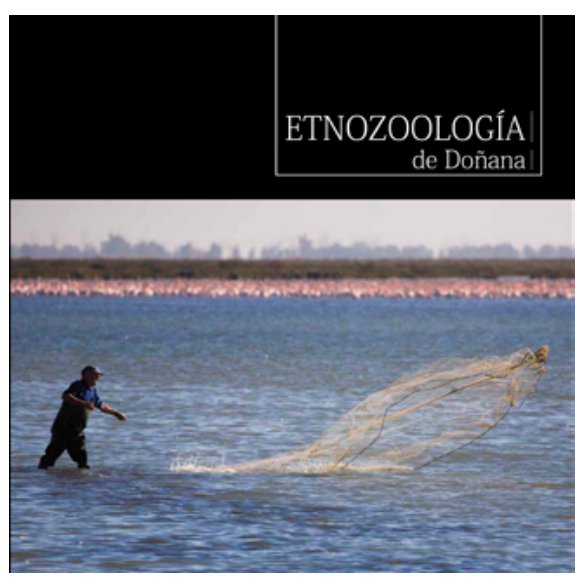

Cubierta de Etnozoología de Doñana 


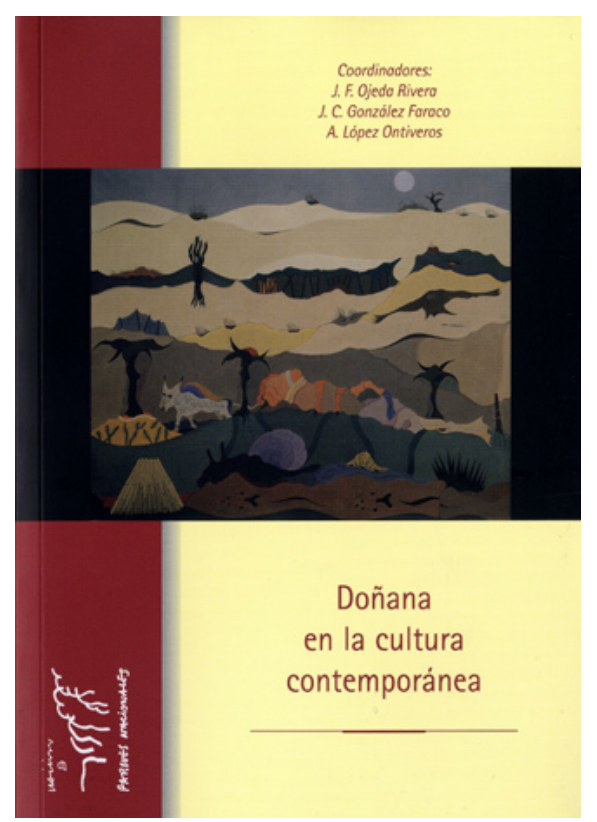

Cubierta de Doñana en la cultura contemporánea

\section{Patrimonio cultural artístico contemporáneo}

Debido a la complejidad, potencia y trascendencia de Doñana como arquetipo del patrimonio, durante algo más del último siglo se ha convertido también en un concepto-objeto de atracción para la creación artística. Por tanto, consideramos justificado que al proponer la gestión del patrimonio cultural de Doñana tengamos también en consideración al patrimonio artístico, tanto histórico como contemporáneo.

En este sentido, resulta fundamental citar una referencia bibliográfica clave como es Doñana en la cultura contemporánea, que en su introducción expone:

"Se abre así la última fase en su construcción cultural, marcada por la emergencia de su discurso ambiental contemporáneo, asociado a toda una batería de agentes y acciones de promoción, difusión y educación que van convirtiendo a Doñana en una gran metáfora de sí misma. Yuxtapuesta y hasta adherida a la imagen mítica, acabada y selectiva de la Doñana ilustrada y romántica, emerge ahora una Doñana polisémica -científica/popular/política- más etérea y expansiva, que se convierte en referencia universal de todo: tradición y seña de identidad local, escenario sagrado, objeto científico, literario y artístico, mercancía verde, santuario natural, reclamo turístico, baza política... Mosaico apenas articulado cuya única condición estable es su propio dinamismo: Doñana es ya un artefacto posmoderno.

La lectura nostálgica del último párrafo podría quizás inducir a la idea de que este libro pretende ser el relato de una degeneración paulatina. Muy al contrario, nuestra intención al concebirlo como tal ha sido y es la de poner de relieve la vitalidad de un proceso de construcción cultural tan rico y dinámico que se resiste a una mirada unilateral, disciplinar o simple. Precisamente la pluralidad y convergencia de miradas nos acercará a la complejidad de una realidad y de un proceso histórico, en los que será inevitable el encuentro con una mixtura de producciones y reproducciones culturales.

En definitiva, este libro coral sobre Doñana en la cultura contemporánea se origina a partir de una honesta proposición, casi un desafío, a una serie de autores -relacionados con Doñana por experiencias personales intensas y por contrastados conocimientos profesionales- de comprometerse en la aventura de contemplar y narrar "sus respectivas Doñanas" por el sendero de la cultura contemporánea. Dicha vía nos traslada a lo abstracto, a lo conceptual, incluso a lo virtual. A través de ella se ha ido construyendo una Doñana cada día más compleja y más líquida y universalizable, hasta el punto de convertirla en una palabra, un texto, un concepto, una construcción volátil y metafórica, especialmente adecuada -por cierto- para su misma physis magmática y primordial" (OJEDA RIVERA; GONZÁLEZ FARACO; LÓPEZ ONTIVEROS, 2006: 10-11). 


\section{Doñana en la narrativa}

Responsable: Juan Villa Díaz.

Proyecto de investigación n. ${ }^{\circ}$ 04/2011 del espacio natural Doñana/estación biológica de Doñana-CSIC.

El objetivo genérico de esta actuación ha consistido en realizar una recopilación e inventario de la presencia de Doñana en publicaciones de narrativa de todos los tiempos, analizando e interpretando dichos textos.

El proyecto se llevó a cabo en Doñana a lo largo del año 2011, y prorrogado durante el siguiente, una de cuyas principales iniciativas consistió en la publicación de una serie de artículos que integraron la sección denominada "Doñana, las otras huellas", que los diarios Odiel Información y seguidamente El Periódico de Huelva editaron cada lunes en su contraportada, desde el día 14 de febrero de 2011 hasta el 23 de enero de 2012. La recopilación de estos artículos ha sido publicada recientemente bajo la denominación homónima (VILLA DÍAZ; SERVETO I AGUILÓ, 2013).

Otras acciones de este proyecto han sido: la recopilación e interpretación de la presencia de Doñana en la narrativa, y la consecuente elaboración y exposición de la ponencia "Doñana en la novela; una visión panorámica de la presencia del espacio natural en la novela contemporánea" en diversos institutos de enseñanza secundaria y bibliotecas públicas andaluzas, así como su publicación en la revista Ería (OJEDA RIVERA; VILLA DÍAZ, 2012); el diseño y realización de una serie de rutas literarias en el parque nacional; $y$, finalmente, la celebración del Encuentro "La Doñana contada: homenaje a Caballero Bonald" en la Universidad Internacional de Andalucía (entre el 13 y el 15 de julio de 2011), escritor galardonado con el Premio de Literatura en Lengua Castellana Miguel de Cervantes.

Por último, otra de las finalidades del proyecto ha consistido en la toma de notas y vivencias in situ para la redacción de una próxima novela del autor, cuyo escenario fundamental se desarrolla en La Vera del parque nacional.

\section{Paisaje}

A partir de la consideración del paisaje como un hecho cultural (CONVENIO, 2000), también se plantea la propuesta de incorporarlo a los objetivos de gestión del patrimonio cultural de Doñana.

Conservación de los paisajes de La Vera. Hacia nuevos retos transdisciplinares y creativos

Responsables: Juan Francisco Ojeda Rivera, César López, Águeda Villa Díaz et ál., Universidad Pablo de Olavide y Universidad de Sevilla.

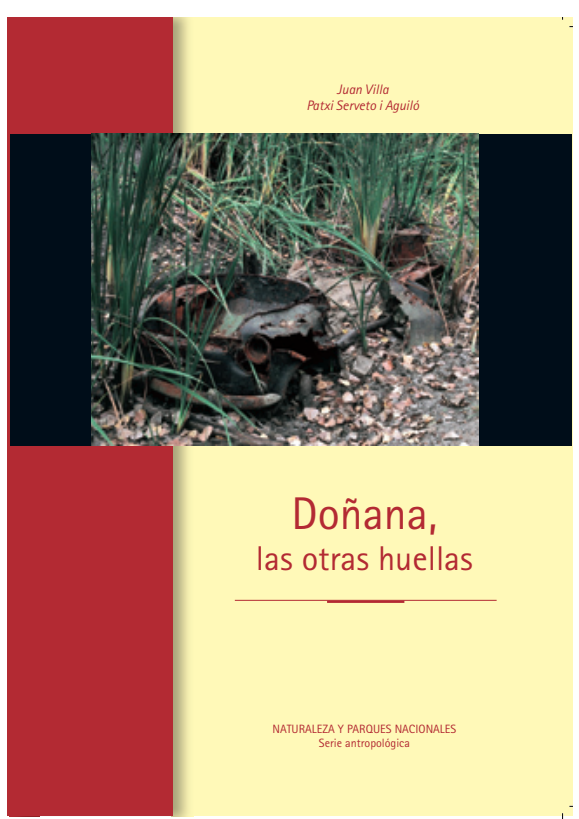

Cubierta de Doñana, las otras huellas

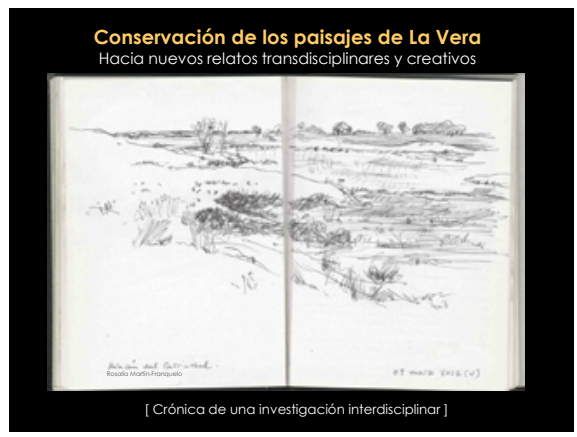

Imagen inicial de la presentación del proyecto Archivo documental de percepciones y representaciones de paisajes andaluces para las Jornadas de investigación sobre la conservación de Doñana (Estación biológica de Doñana/CSIC, 2014) 

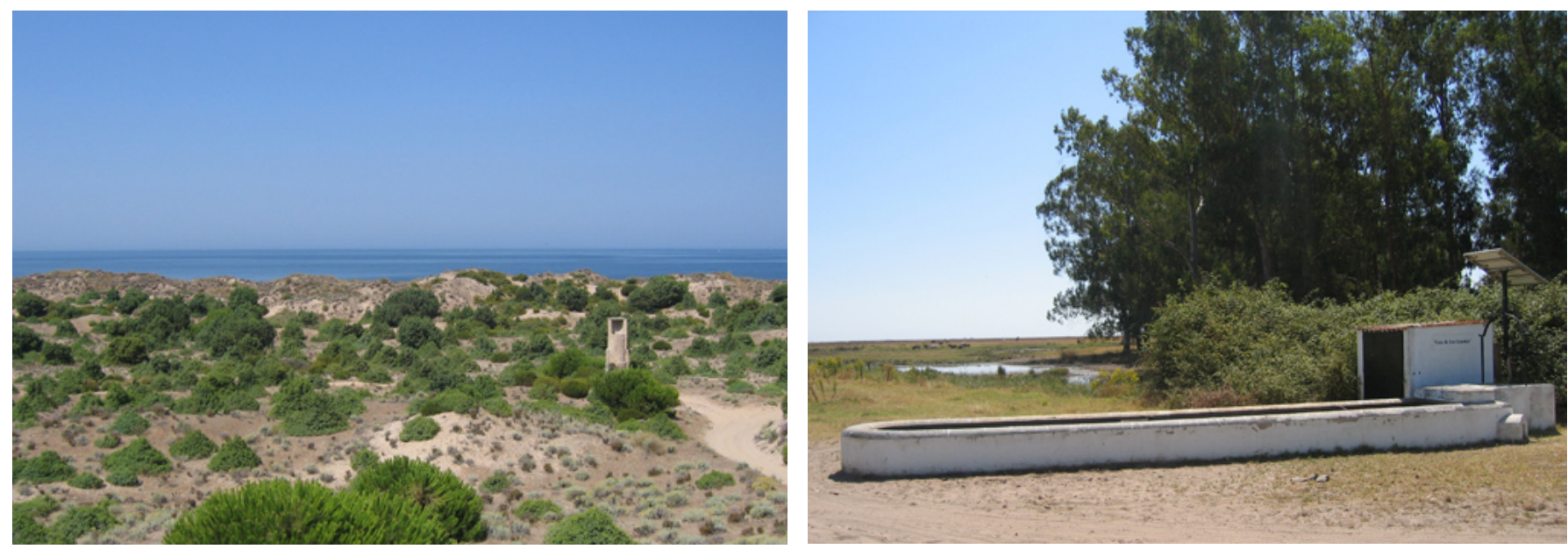

Pozo de agua del Inglesillo, "testigo" del paso de las dunas

Abrevadero de la casa de los Guardas, en La Vera | fotos Isabel Durán

Proyecto de excelencia del P.A.I.D.I. Archivo documental de percepciones y representaciones de paisajes andaluces (P09-HUM-5382).

Proyecto de investigación n. ${ }^{\circ}$ 35/2011 del espacio natural Doñana/estación biológica de Doñana-CSIC, llevado a cabo entre 2011 y 2015.

El objetivo genérico de esta actuación ha consistido en promover las comprensiones e inducir y/o subrayar los valores patrimoniales de paisajes significativos andaluces, mediante relatos creativos y comprensibles de los mismos trabajando desde una lectura hermenéutica e interdisciplinar.

Los ámbitos paisajísticos elegidos han sido: Doñana: La Vera, como núcleo del parque nacional, las marismas arroceras, como ámbito estacional y cambiante, y las arenas del Abalario, como territorio de experimentaciones coloniales; Subbéticas cordobesas: paisajes kársticos y núcleos habitacionales; Sierra Morena de Huelva: ámbitos cumbreños, ámbitos centrales y solanas de piedemonte; paisajes urbanos: jardines de Sevilla, fachadas marítimas de Cádiz y núcleos urbanos de algunos puertos secundarios andaluces.

Las fases del método de lectura paisajística han sido: I. Se parte de una recopilación pluridisciplinar de informaciones sobre el ámbito a estudiar: definición de claves comprensivas (espaciales, territoriales y paisajísticas) y elección de paisajes significativos. Cuaderno o guía de visita. II. Se desarrollan lecturas compartidas (interdisciplinares y hermenéuticas) de los paisajes significativos: límites, componentes principales, atributos y núcleos de sentido. Hacia unos nuevos relatos. III. Se termina elaborando trabajos transdisciplinares y creativos, que puedan llegar a constituir relatos nuevos y actuales de unos paisajes realmente reconocidos, estimados y valorados gracias a los distintos relatos que en cada contexto histórico se han ido efectuando sobre ellos (OJEDA RIVERA; ALONSO MIURA; MARTíN FRAQUELO et ál., 2014: 36-37). 

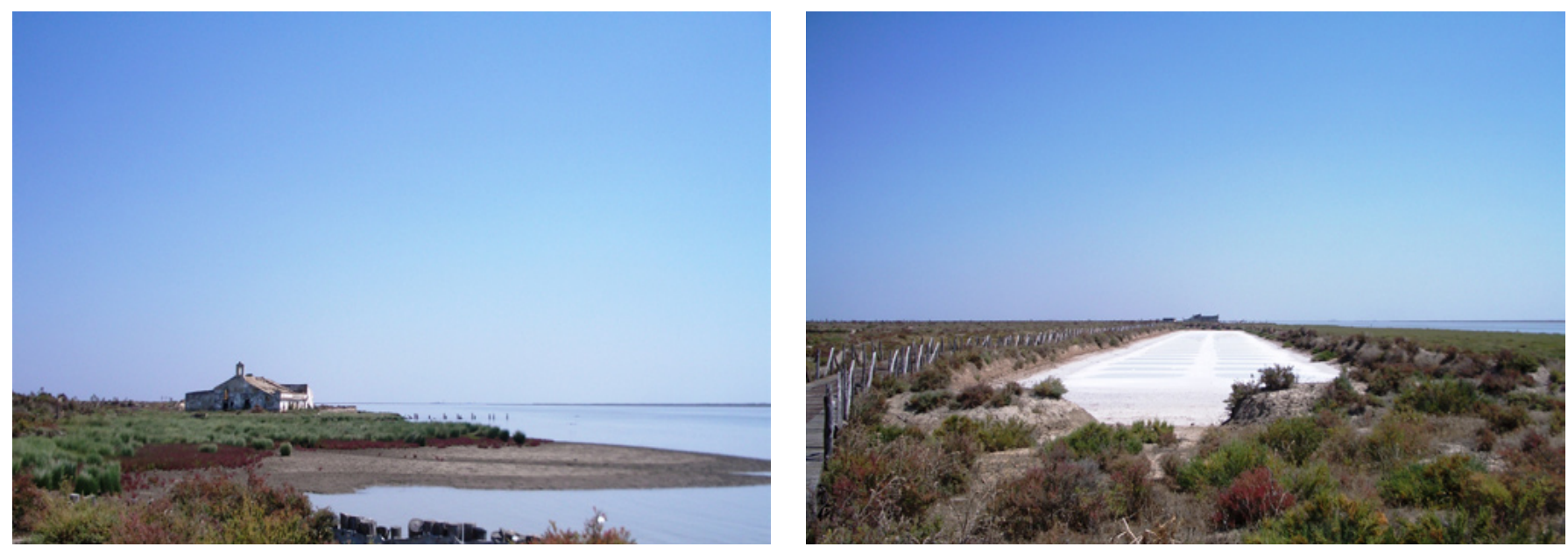

\section{LA GESTIÓN DEL PATRIMONIO CULTURAL DE DOÑANA EN LA PLANIFICACIÓN DEL ESPACIO NATURAL}

Salinas de San Diego, junto al río Guadalquivir

La planificación constituye un instrumento básico de gestión de los espacios naturales protegidos, cuyos documentos normativos son los planes de ordenación de los recursos naturales (PORN) y los planes rectores de uso y gestión (PRUG), así como los programas sectoriales. En este sentido, constituye el objetivo principal del PRUG del espacio natural Doñana garantizar su administración y gestión, así como establecer las bases para los distintos programas sectoriales que lo desarrollen, en el marco de las directrices generales establecidas en el PORN y en el Plan Director de la Red de Parques Nacionales (LEY 8/1999). Una de estas directrices establece la preservación de todos los recursos culturales a través de los adecuados programas de estudio, tratamiento y protección, mientras que otra establece la preservación del paisaje como uno de los principales valores de los parques (REAL DECRETO 1803/1999).

En la vigente planificación de Doñana, independiente aún la correspondiente al parque nacional (DECRETO 48/2004) de la del parque natural (DECRETO 97/2005), se plantea la gestión del patrimonio cultural y del paisaje de forma dispar, ya que mientras en el parque nacional forma parte consustancial del mismo, en el parque natural apenas se citan. En todo caso, el tratamiento del patrimonio cultural y del paisaje se caracteriza fundamentalmente por contemplar parcialmente sus contenidos, por establecer apenas vínculos entre ellos y en menor medida con el patrimonio natural, y por abordar su gestión con acciones independientes y no mediante algún instrumento de planificación, exceptuando los programas sectoriales de la mayor parte de los aprovechamientos tradicionales. 
3

Patrimonio cultural material: mueble (artesanía, artilugios, ingenios y maquinaria, manuscritos, mobiliario, monedas, útiles y herramientas, etc.); inmueble (yacimientos y zonas arqueológicas, lugares de interés etnológico, industrias y lugares de interés industrial, y zona patrimonial); y subacuático (pecios, restos de naufragios, ruinas y poblaciones sumergidas, etc.). Patrimonio cultural inmaterial: conocimientos y estudios perceptivos e identitarios; conocimientos, usos y aprovechamientos tradicionales relacionados con la naturaleza y el universo, en general, y los recursos naturales de Doñana en particular; creencias, leyendas, rituales, símbolos, usos sociales, y recursos naturales con significación cultural; eventos festivos o lúdicos; Historia humana de Doñana complementada con la Historia natural; modos de vida tradicionales; patrimonio lingüístico; técnicas artesanales tradicionales; recursos culturales de carácter científico, educativo e interpretativo... Patrimonio cultural artístico contemporáneo: artes culinarias; artes escénicas; artes plásticas; artes visuales; y literatura..

4

Paisaje: ecología del paisaje (criptosistema y fenosistema, usos y aprovechamientos de los recursos naturales con incidencia en el paisaje...), y paisaje perceptual (capacidad paisajística: calidad visual del paisaje, potencialidad paisajística, fragilidad visual de paisaje, uso público...).
No obstante, uno de los resultados de mayor interés de la evaluación de la vigente planificación respecto del patrimonio cultural de Doñana lo constituye la elaboración y tramitación de la Documentación técnica para la inscripción en el Catálogo general del patrimonio histórico de Andalucía del conjunto de bienes inmuebles y actividades etnológicas en el parque nacional de Doñana como bien de interés cultural con la tipología de zona patrimonial, iniciada de oficio por la Consejería de Cultura a partir de la propuesta del PRUG "Elaboración de un catálogo de bienes culturales existentes en el Parque (Nacional)".

En la actualidad, la Consejería de Medio Ambiente y Ordenación del Territorio está acometiendo la revisión de la planificación de Doñana (ACUERDO de 29 de octubre de 2013) y, respecto de su incidencia sobre el patrimonio cultural y el paisaje, cabe destacar tres de los factores clave del proceso: que el Espacio Natural disponga de un PORN y de un PRUG únicos, que responda a la evolución y experiencia derivada de la labor de gestión y de la evaluación de la planificación, y que incorpore las novedades normativas y conceptuales que se han ido produciendo desde la aprobación vigente.

En base a ello, se plantean los siguientes criterios básicos para la elaboración de la propuesta de gestión del patrimonio cultural y del paisaje en la nueva planificación del END:

> La conservación del patrimonio cultural y del paisaje, además del patrimonio natural, debe condicionar también las acciones que se desarrollen en el Espacio Natural, contribuyendo al desarrollo sostenible del territorio.

$>$ Deben identificarse sinergias y vínculos entre el patrimonio cultural y el natural, incluyendo el paisaje, con la finalidad de incorporar el patrimonio integral como interacción entre todos ellos.

$>$ Deben contemplarse todas las disciplinas que integran el patrimonio cultural $^{3}$, así como el estudio del paisaje aplicando diversas metodologías ${ }^{4}$.

> Debe elaborarse un instrumento para la gestión del patrimonio cultural, tal que un programa sectorial o, en su defecto, un programa de trabajo y un catálogo de bienes, en consonancia con la correspondiente normativa sectorial y colaboración institucional; en el caso del paisaje, se propone la elaboración de un catálogo de unidades y un manual de gestión.

$>$ Consecuentemente con los criterios anteriores, debe promoverse el aumento de la investigación sobre el patrimonio cultural y el paisaje, y sobre las ciencias sociales en general.

$>$ Por último, debe tenerse presente que el patrimonio cultural y el paisaje del Espacio Natural se interrelacionan con los del resto de la comarca de Doñana. 


\section{ANEXO}

Extracto de textos ilustrativos pertenecientes a la ficha general de la Documentación técnica para la inscripción en el CGPH del conjunto de bienes inmuebles $y$ actividades etnológicas en el parque nacional de Doñana como bien de interés cultural con la tipología de zona patrimonial (pp. 04-12, 35-36)

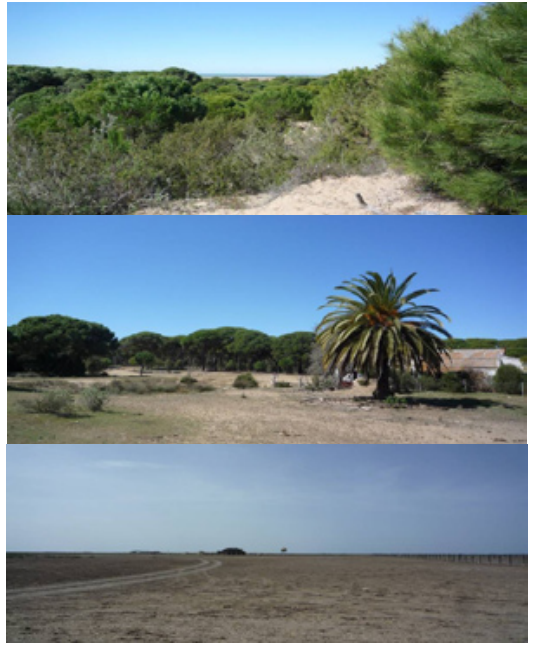

DOCUMENTACIÓN TÉCNICA PARA LA INSCRIPCIÓN EN EL CGPHA DEL CONJUNTO DE INMUEBLES Y ACTIVIDADES ETNOLÓGICAS EN EL PARQUE NACIONAL DE DOÑANA COMO BIEN DE INTERÉS CULTURAL CON LA TIPOLOGÍA DE ZONA PATRIMONIAL.

Ficha general

Redactor: Fermin Seño Asencio (Antropólogo social)

Colaboradores: Paqui Florido Moro (Cartografía)

Patxi Serveto i Aguiló (Coordinación desde el ENP de Doñana).

Fecha: Junio 2012.
"4. Justificación de la inscripción; 4.1. Valores patrimoniales. El Parque Nacional de Doñana, de excepcionales valores ecológicos, constituye un ámbito territorial conformado por un conjunto patrimonial diverso de bienes culturales representativos de diferentes procesos de transformación y antropización en el territorio a lo largo de la historia. Estos procesos materializados en distintos usos y aprovechamientos representan en la actualidad relevantes testimonios de la actividad humana que permiten explicar la actual configuración espacial de este Espacio Natural Protegido (ENP).

Es precisamente la importancia del territorio en su doble vertiente como testimonio cultural y dimensión medioambiental, lo que nos permite valorar patrimonialmente la relación existente entre ambas dimensiones en el marco de las líneas de la protección de la naturaleza.

Uno de los principales valores patrimoniales que se argumentan para la inscripción en el CGPHA, por tanto, es el valor histórico del poblamiento a lo largo de las épocas, un hecho que ha marcado la dimensión territorial en el Parque Nacional, con el desarrollo de diversos usos y aprovechamientos. La importancia histórica de la huella humana sobre Doñana se manifiesta en Cerro del Trigo, primer testimonio humano en el área en torno a una factoría de garum y salazón, aunque existen vestigios importantes en la zona todavía por investigar, que pueden remontarse al Neolítico y Edad del Cobre. A lo largo de la historia el proceso de antropización en el área ha venido marcado por un poblamiento expresado en distintas etapas que son ilustrativas de la conformación de estos paisajes: desde el periodo del antiguo régimen con el surgimiento de la etapa predatoria (de caza y recolección) durante los siglos XVI-XVII, el periodo ilustrado durante el XVIII (con el inicio de la etapa forestal y la aparición de los poblados de chozas), la propiedad en el XIX (con el desarrollo de la ganadería extensiva y el establecimiento de los hatos y casas de guardería), hasta llegar a la etapa proteccionista, con la creación del Parque Nacional a mediados del siglo $X X$.

Al valor histórico que representa el área hay que añadir el valor arquitectónico expresado en distintas tipologías de construcciones que son ilustrativas de los periodos históricos en los 
que primó un determinado aprovechamiento productivo: los palacios y pabellones de caza, los hatos y casas de guardería, los poblados de chozas, las casas salineras, sin olvidar las construcciones litorales dispersas a lo largo de la costa cuya misión era el control, la defensa o la vigilancia sobre un espacio abierto al mar, como las torres almenara, los cuarteles de carabineros, de la guardia civil, los faros, y los búnkeres de la Segunda Guerra Mundial. Todo este patrimonio edificado representa un conjunto de enorme valor provisto de características arquitectónicas singulares y particularizadas que forman parte del paisaje de Doñana en el Parque Nacional.

Por otra parte, de los usos y aprovechamientos desarrollados en el área se desprende un valor inmaterial que justifica por sí mismo la consideración de Doñana como patrimonio cultural, conceptualizado desde dos ángulos: como expresión significativa de distintas culturas del trabajo, modos de vida, oficios y otros saberes derivados del manejo del medio (guardas, ganaderos, yegüerizos, carboneros, piñeros, apicultores, pescadores, mariscadores, etc.), asumidos en el marco de la protección de la naturaleza; y como ámbito espacial significativo de dos expresiones rituales festivas que ponen de manifiesto las relaciones de las poblaciones del entorno con el espacio natural: la Romería del Rocío y la Saca de las yeguas, con especiales connotaciones en las formas de apropiación del territorio. En el caso de la romería y las peregrinaciones del Rocío se constata la relación de todos los municipios de los alrededores con el Santuario, siendo especialmente significativo en el ámbito, el tránsito de las hermandades de Cádiz por la vía pecuaria de Sanlúcar que comunicaba el antiguo señorío de los Duques de Medina Sidonia desde su capital en Sanlúcar de Barrameda hasta el Condado de Niebla, atravesando de sur a norte todo el Parque Nacional. En el caso de la Saca, la apropiación se produce por parte del municipio de cuyos derechos sobre la ganadería se remontan al Antiguo Régimen, Almonte.

Estas connotaciones que poseen los rituales también se expresan en los aprovechamientos históricamente desarrollados, entendidos como formas de vinculación de las poblaciones con el entorno de Doñana. En el Parque Nacional los vínculos de las poblaciones con las formas de aprovechamiento se observan en la continuidad de la ganadería reivindicada por Almonte e Hinojos; la pesca y el marisqueo, desarrollada por vecinos de Pilas y Sanlúcar; y los aprovechamientos forestales, de los que los vecinos de Sanlúcar a través del carboneo y la explotación del pinar se beneficiaron durante siglos.

Tanto las culturas del trabajo relacionadas con los usos y aprovechamientos, como las relaciones de estos dos rituales con el ámbito constituyen el patrimonio inmaterial del Parque Nacional.

El sustrato histórico del conjunto de actividades humanas presentes y su huella en el paisaje, ya sea a través de la presencia de inmuebles y actividades ofrece en la actualidad un valor de uso y disfrute para la comunidad en el marco de la protección de la naturaleza, complementando este legado cultural los valores ambientales, paisajísticos y naturales de Doñana de manera completa e indivisible.

4.2. Justificación de la inscripción y la figura de protección. Una de las razones principales que justifican la inscripción del patrimonio cultural de Doñana en el Catálogo General de Patrimonio Histórico Andaluz es el tratamiento y las disposiciones normativas que se desprenden del documento que reglamenta el Parque Nacional, el Plan Rector de Uso y Gestión, aprobado en febrero de 2004 [...].

A través de este documento puede constatarse el papel que el patrimonio cultural tiene en el marco de la planificación ambiental del Parque Nacional, así como las directrices que afectan directa e indirectamente a los elementos que forman parte del mismo. Estas cuestiones resultan fundamentales para proceder a poner en marcha la acción proteccionista por parte de la Consejería de Cultura ya que el régimen jurídico del Parque Nacional establece una clara delimitación de usos en funciones de las características ecológicas de los diversos ecosistemas, delimitando las actividades permitidas (investigación, turismo, aprovechamientos tradicionales, etc.) y la finalidad de las instalaciones en ellas localizadas (poblados, palacios, casas de guardas, etc.) [...].

A tenor de lo expuesto, considerando los instrumentos jurídicos de los que se sirve la Consejería, teniendo en cuenta los 
valores patrimoniales identificados en este ámbito territorial y estimando la complementariedad de los mismos con la protección de los valores en el marco de la conservación de la naturaleza y el ámbito del Parque Nacional, se propone como figura de protección la Zona Patrimonial entendida como "aquellos territorios o espacios que constituyen un conjunto patrimonial diverso y complementario, integrado por bienes diacrónicos representativos de la evolución humana, que poseen un valor de uso y disfrute para la colectividad y, en su caso, valores paisajísticos y ambientales.

El objeto no es otro sino el de singularizar y reconocer los testimonios culturales de unas formas de interrelación entre el ser humano y su entorno para complementar los valores ambientales y paisajísticos propios de este espacio.

[...] A las razones patrimoniales esgrimidas que constituyen el interés en el Parque Nacional como ejemplo de confluencia humana y territorio, se justifica el interés por coordinar las acciones en materia de patrimonio cultural en este ENP.

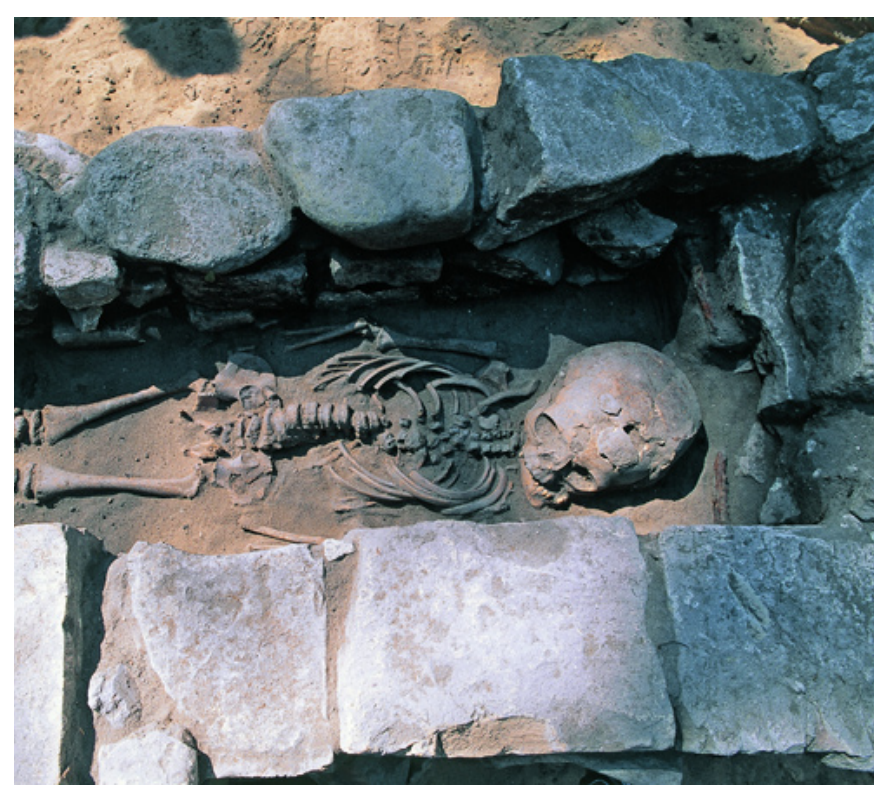

Esqueleto de un niño correspondiente a una cetaria romana del siglo II d. C. (excavación de la Universidad de Huelva en el yacimiento arqueológico del cerro del Trigo) | foto Patxi Serveto (VILLA DÍAZ; SERVETO I AGUILÓ, 2013)
En este sentido se señala que en el área propuesta sólo existen con protección jurídica por parte de la Consejería de Cultura las torres almenara (BIC por Ministerio de Ley) y el Espaciosubacuático Arenas Gordas-Desembocadura del Guadalquivir, mediante Orden de 20 de abril de 2009, por la que se declara como Zonas de Servidumbre Arqueológica 42 espacios definidos en las aguas continentales e interiores de Andalucía, mar territorial y plataforma ribereña al territorio andaluz [...].

5. Descripción del Bien; 5.1. Introducción: la confluencia entre acción antrópica y ecosistemas. Como afirman Granados y Ojeda (1994) el territorio que conforma el estuario del Guadalquivir es producto de un largo y constante proceso de relleno que aún no ha terminado y en el que tanto la dinámica fluvial como los flujos marinos actúan de vectores fundamentales. Una gran parte de esta extensión la conforma el Parque Nacional de Doñana que cuenta con 50.720 hectáreas. Las características de estos terrenos son la horizontalidad o planitud topográfica, los contrastes biogeográficos y la génesis reciente de los mismos. De la componente horizontal se produce una elaborada trama de geofacies, cada una de ellas con una personalidad edáfica y ecodinámica propia. Los contrastes biogeográficos son perceptibles en el encuentro de dunas con corrales y marismas, de matorrales xerofíticos con matorrales hogrofíticos. Otros rasgos singulares de la morfología geológica de este territorio son la movilidad de los sistemas dunares, los ciclos de inundación y relleno marismeño, y la misma variabilidad histórica de la línea de costa. [...]

En estas tres unidades ambientales la acción humana ha sido un factor de diversificación ecológica a lo largo de la historia, como bien ha estudiado Granados Corona (1988). El poblamiento disperso y poco concentrado en el área se ha traducido en una gran influencia para la configuración actual del territorio, marcado por los distintos usos y aprovechamientos. Las formas en las que estos aprovechamientos se han materializado han dejado una huella claramente visible en el medio (Granados Corona 1988, Granados y Ojeda 1994). [...]

7. Datos Históricos; 7.1. Introducción. La consideración de Doñana como patrimonio cultural pasa por comprender el espacio como el resultante de una serie de procesos que han gene- 


\section{ANEXO}

rado la transformación de un medio físico determinado en un espacio socialmente construido, es decir en territorio, fruto de la relación hombre-naturaleza. Por tanto, será el estudio de sus características físicas, del papel de la actividad antrópica en su uso, y de los procesos de transformación llevados a cabo hasta conformar la realidad actual, lo que constituirá la fuente de la que extraer los datos necesarios para establecer la dimensión del patrimonio cultural en el área.

A partir de lo señalado, hemos de destacar lo que supone la consideración del patrimonio cultural como un recurso en los ENP. Este acercamiento, implica desterrar la idea de los espacios naturales en general, y de Doñana en particular, como lugares vírgenes donde la intervención humana no ha tenido lugar, permitiéndonos el acercamiento bajo la óptica de que sus unidades ambientales han sido modificadas por el hombre de tal modo que se han generado nuevos ambientes naturales. En base a esta relación debemos reflexionar sobre la importancia del factor humano en estos espacios y las consecuencias negativas que supondría para estas áreas la ruptura de esta relación, a raíz de una concepción restringida del territorio, en el concepto de patrimonio cultural utilizado en el modelo de desarrollo sobre el que se basa la gestión de los mismos. Es por ello que desde estas páginas se apuesta por la consideración del territorio de Doñana como el resultado de un proceso histórico donde los intereses propios de cada período derivaron en un manejo concreto de sus recursos naturales, adecuándolos a las necesidades de sus propietarios y usuarios". 


\section{BIBLIOGRAFÍA}

- AcostA, A.; MATEOS, J.; SÁNCHEZ, P. et ál. (2011) Guía turística Comarca de Doñana. Disfruta de sus encantos. Almonte: Fundación Doñana 21, 2011

- ACOSTA NARANJO, R. (2004) Pan de marisma. Madrid: Ministerio de Medio Ambiente, Organismo Autónomo de Parques Nacionales, Publicaciones del Comité Español del Programa MaB y de la Red IberoMaB (UNESCO), n. ${ }^{\circ} 6$ noviembre, 2004

- ACUERDO de 29 de octubre de 2013, del Consejo de Gobierno, por el que se aprueba la formulación del Plan de Ordenación de los Recursos Naturales y el Plan Rector de Uso y Gestión del Espacio Natural de Doñana. Boletín Oficial de la Junta de Andalucía, n. ${ }^{\circ} 241$, de 11 de diciembre de 2013

- CABAllero BONALD, J. M.; ALONSO MIURA, R (2005) Los poderes de Doñana. En DíAZ VELÁZQUEZ, F. (coord.) Andalucía, naturaleza y arte. Sevilla: Junta de Andalucía, EGMASA, 2005, pp. 23

- CANTOS MENGS, F. J.; DE TORRES SUÁREZ, Á.; BELTRÁN DÍAZ, N. (coord.) (2010) Guía de reservas de la biosfera españolas; Armonía hombre-naturaleza. Madrid: Organismo Autónomo Parques Nacionales, 2011

- COBO LÓPEZ, M. P.; TIJERA JIMÉNEZ, R. E. (2013) Etnozoología de Doñana. Mancomunidad de Desarrollo y Fomento del Aljarafe, 2013, p. 3 (Memoria Final del Proyecto de Investigación $n^{\circ}$ 23/2012 del Espacio Natural de Doñana/EBD-CSIC)

- CONVENCIÓn sobre la protección del patrimonio mundial, cultural y natural (1972). UNESCO <http:// whc.unesco.org/archive/convention-es.pdf> [Consulta: 14/02/2014].

- CONVENIO europeo del paisaje, de 20 de octubre de 2000. Florencia: Consejo de Europa, Ministerio español de Asuntos Exteriores, 2002 <http://www.mcu.es/patrimonio/ docs/Convenio_europeo_paisaje.pdf> [Consulta: 14/02/2014]

- DECLARACIÓN DE LOS PARQUES NATURALES [en línea]. Ambientum.com <http://www.ambientum.com/ enciclopedia_medioambiental/natura/Declaracion_de_los_ parques_naturales.asp> [Consulta 21/01/2014]

- DECRETO 48/2004, de 10 de febrero, por el que se aprueba el Plan Rector de Uso y Gestión del Parque Nacional de Doñana. Boletín Oficial de la Junta de Andalucía, n. ${ }^{\circ}$ 105, de 1 de junio de 2005

- DECRETO 97/2005, de 11 de abril, por el que se establece la ordenación del parque nacional y parque natural de doñana <http://www.cma.junta-andalucia.es/medioambiente/web/ Bloques_Tematicos/Patrimonio_Natural._Uso_Y_Gestion/ Espacios_Protegidos/PORN/PORN_PRUG_Donana/ decreto.pd $\bar{f}>$ [Consulta: 24/02/2014]
- DURÁN SALAdO, M. ${ }^{a}$ I. (2003) La Otra Banda. Sanlúcar de Barrameda en la territorialización de Doñana: siglos XIVXX. Sevilla: Consejería de Cultura, 2003

- El FORTALECIMIENTO de la biodiversidad en Doñana (2012) Universidad de Sevilla, Departamento de Antropología Social, Grupo de Investigación Cultura, Ecología y Desarrollo de Pequeños Territorios (GICED) $<$ http://personal.us.es/racosta/Articulos/BIODIVERSIDAD DONANA.pdf> (Consulta: 14/02/2014)

- FUREST, GUTIÉRREZ A; ESTÉVEZ HERRANZ, A. (coord. fases I y II) (1988-1992) Recuperación del Patrimonio Cultural de Doñana y su Entorno (vol. I-XIII). Madrid: Ministerio de Cultura; Ministerio de Asuntos Sociales; Instituto de la Juventud, 1988-1992

- GALLEGO, E. (1997) Protección y conservación de Espacios Naturales y del Patrimonio Geológico. Zubía (revista de ciencia). Instituto de Estudios Riojanos, n. ${ }^{0} 16$, 1998, pp. 155-179

- GRANADOS CORONA, M. (1987) Transformaciones Históricas de los Ecosistemas del Parque Nacional de Doñana. Tesis doctoral inédita

- gRANAdos coronA, M.; OJEDA RIVERA, J. F. (1994) Doñana. Paisaje y poblamiento. Edificaciones en el Parque Nacional. Sevilla: Junta de Andalucía, 1994

- LEY 2/1989, de 18 de julio, por la que se aprueba el Inventario de Espacios Naturales Protegidos de Andalucía, y se establecen medidas adicionales para su protección. Boletín Oficial de la Junta de Andalucía, n. ${ }^{\circ} 60$, de 27 de julio de 1989 <http://juntadeandalucia.es/boja/1989/60/1>

- LEY 8/1999, de 27 de octubre, del Espacio Natural de Doñana. Boletín Oficial de la Junta de Andalucía, n. ${ }^{\circ}$ 137, de 25 de noviembre de 1999

- LEY 5/2007, de 3 de abril, de la Red de Parques Nacionales. Boletín Oficial del Estado, n. ${ }^{\circ} 81$, de 4 abril de 2007

- LEY 14/2007, de 26 de noviembre, del Patrimonio Histórico de Andalucía. Boletín Oficial de la Junta de Andalucía, n. ${ }^{\circ}$ 248, de 19 de diciembre de 2007

- LEY 42/2007, de 13 de diciembre, del Patrimonio Natural y de la Biodiversidad. Boletín Oficial del Estado, n. ${ }^{\circ} 299$, de 14 de diciembre de 2007

- MALLARACH, J. M.; COMAS, E.; DE ARMAS, A. (2012) El patrimonio inmaterial: valores culturales y espirituales. Manual para su incorporación en las áreas protegidas. Madrid: Fundación Fernando González Bernáldez, 2012 (Serie de manuales EUROPARC-España; Programa de trabajo para las áreas protegidas 2009-2013, Manual 10)

- MATEOS MATEOS, J. (2011) Patrimonio Cultural de la Comarca de Doñana. Curso "Gestión de espacios 


\section{BIBLIOGRAFÍA}

naturales y conservación de la biodiversidad". Plan Andaluz de Formación Ambiental. Consejería de Medio Ambiente (Ponencia, documentación del curso, inédita, pp. 08-14)

- NUESTRO PATRIMONIO MUNDIAL (2002) The World Heritage Brochure [en línea]. UNESCO, Centro del Patrimonio Mundial. <whc.unesco.org/document/101852> [Consulta 24/01/2014]

- OJEDA RIVERA, J. F. (1987) Organización del Territorio en Doñana y su Entorno Próximo (Almonte). Siglos XVIII$X X$. Madrid: Ministerio de Agricultura, Pesca y Alimentación, Instituto Nacional para la Conservación de la Naturaleza, 1987 (Monografías n. ${ }^{\circ} 49$ )

- OJEDA RIVERA, J. F.; GONZÁlEZ FARACO, J. C.; LÓPEZ ONTIVEROS, A. (2006) Doñana en la cultura contemporánea. Madrid: Ministerio de Medio Ambiente, Organismo Autónomo Parques Nacionales, 2006

- OJEDA RIVERA, J. F.; VILLA DÍAZ, J. (2012) La Doñana contada. País y paisajes de Doñana en la novela contemporánea. Ería. Revista cuatrimestral de geografía. Universidad de Oviedo, 2012 [en línea] <http://www. unioviedo.es/reunido/index.php/RCG/article/view/9810> [consulta: 13-02-2014]

- OJEDA RIVERA, J. F.; ALONSO MIURA, R.; MARTÍN FRANQUELO, R. et ál. (2014) Conservación de los paisajes de La Vera. Hacia nuevos relatos transdisciplinares y creativos. En JORNADAS de investigación sobre la conservación de Doñana. Sevilla, 6 y 7 de febrero de 2014. [en línea] Ministerio de Economía y Competitividad, Consejo Superior de Investigaciones Científicas, Estación Biológica de Doñana, 2014, pp. 36-37 <http://www.ebd. csic.es/Website1/ZEsp/Actividades/Divulgacion/Eventos. aspx> [Consulta: 05/02/2014]

- PAREJO DELGADO, C.; SERVETO AGUILÓ, P. (2008) Paisajes de Huelva. Huelva: Diputación Provincial de Huelva, 2008

- PROgRAMA de trabajo para las áreas protegidas 20092013 (2009) [en línea] Madrid: FUNGOBE (Fundación Interuniversitaria Fernando González Bernáldez para los Espacios Naturales), 2009 <http://www.redeuroparc. org/publicaciones/programatrabajo.pdf> (Consulta: 14/02/2014)

- REAL DECRETO 1803/1999, de 26 de noviembre, por el que se aprueba el Plan Director de la Red de Parques Nacionales. Boletín Oficial del Estado, n. ${ }^{\circ} 297$, de 13 de diciembre de 1999

- RESOLUCIÓN de 26 de enero de 2010, de la Dirección General de Desarrollo Sostenible del Medio Rural, por la que se publica el Convenio de colaboración, entre el Ministerio de Medio Ambiente, y Medio Rural y Marino y la Junta de Andalucía, de actuaciones de desarrollo sostenible en las reservas de la biosfera de Cabo de Gata-Níjar, Sierras de Cazorla Segura y Las Villas, Dehesas de Sierra Morena, Doñana, Sierra de Grazalema, Intercontinental del Mediterráneo, Marismas del Odiel y Sierra Nevada. Boletín Oficial del Estado, n. ${ }^{\circ}$ 34, de 8 de febrero de 2010

- RINCón CALDERóN, J. M. (2012) Las Edificaciones en Doñana: Estrategias de Eficiencia. Trabajo fin de máster "Ciudad y Arquitectura Sostenibles", edición 2011-2012, Universidad de Sevilla, inédito

- RINCÓN CALDERÓN, J.M.; SÁNCHEZ FUENTES, D.; GALÁN MARÍN, C. (2014) Las Edificaciones en Doñana: Estrategias de Eficiencia. En JORNADAS de investigación sobre la conservación de Doñana. Sevilla, 6 y 7 de febrero de 2014: Ministerio de Economía y Competitividad, Consejo superior de Investigaciones Científicas, Estación Biológica de Doñana [en línea] <http://www.ebd.csic.es/Website1/ ZEsp/Actividades/Divulgacion/Eventos.aspx> [Consulta: 05/02/2014]

- SEÑO ASENCIO, F.; FLORIDO MORO, F. (2012) Documentación técnica para la inscripción en el CGPH del conjunto de bienes inmuebles y actividades etnológicas en el parque nacional de Doñana como bien de interés cultural con la tipología de zona patrimonial. Huelva: Consejería de Cultura y Deporte, Archivo de la Delegación Territorial de Educación, Cultura y Deporte, 2012

- SOLUCIONES de la naturaleza para los desafíos globales (2013) [en línea]. Unión Internacional para la Conservación de la Naturaleza <http://cmsdata.iucn.org/downloads/uicn spanish_brochure.pdf> [Consulta 21/01/2014]

- RAMSAR (1971) Convención de Ramsar: Convención Relativa a los Humedales de Importancia Internacional [en línea] <http://www.ramsar.org/cda/es/ramsar-documentstexts-convention-on/main/ramsar/1-31-38\%5E20671_4000_ 2 _ > [Consulta 14/02/2014]

- VACAS GUERRERO, T. (2005) Los espacios naturales protegidos: figuras de protección en España. En Actas de XIX Congreso de Geógrafos Españoles: Espacios públicos, espacios privados. Santander: Asociación de Geógrafos Españoles, Universidad de Cantabria, 2005

- VILLA díAZ, J.; SERVETo I AGUILó, P. (2013) Doñana, las otras huellas. Madrid: Ministerio de Agricultura, Alimentación y Medio Ambiente; Organismo Autónomo Parques Nacionales, 2013 (Colección Naturaleza y Parques Nacionales, Serie antropológica)

- VIÑALS, M. J. (Coord.) (2002) El patrimonio cultural de los humedales/Wetland Cultural Heritage. Madrid: Ministerio de Medio Ambiente, Dirección General de Conservación de la Naturaleza, 2002 (Serie antropológica) 